\title{
Monetary Policy and Sectoral Shocks: Did the Federal Reserve React Properly to the High-Tech Crisis?*
}

\author{
Claudio Raddatz $z^{\ddagger}$ \\ DECRG \\ The World Bank
}

\author{
Roberto Rigobon ${ }^{\S}$ \\ Sloan School of Management \\ MIT
}

\begin{abstract}
This paper presents an identification strategy that allows us to study both the sectoral effects of monetary policy and the role that monetary policy plays in the transmission of sectoral shocks. We apply our methodology to the case of the U.S. and find some significant differences in the sectoral responses to monetary policy. We also find that monetary policy is a significant source of sectoral transfers. In particular, a shock to equipment and software investment, which we naturally identify with the high-tech crisis, induces a response by the monetary authority that generates a temporary boom in residential investment and durables consumption but has almost no effect on the high-tech sector. Finally, we perform an exercise evaluating the model's predictions about the automatic and more aggressive monetary policy response to a shock similar to the one that hit the U.S. in early 2001. We find that the actual drop in interest rates we have observed is in line with the predictions of the model.
\end{abstract}

*We thank Ricardo Caballero for helpful comments on a preliminary version of the paper. All remaining errors are ours.

${ }^{\dagger}$ craddatz@worldbank.org.

†The views expressed in this paper are the author's only and do not necessarily represent those of the World Bank, its executive directors, or the countries they represent.

§rigobon@mit.edu 


\section{Introduction}

The long boom in the U.S. during the 1990s came to an end in 2001 with a large decline in information technology (IT) investment. After growing at an annual rate of $16 \%$ during 2000 , IT spending fell by $6 \%$ in 2001, while the NASDAQ lost half its value between September 2000 and March 2001.

In 2001, the The Federal Reserve responded to the end of the IT bubble and the general collapse of the stock markets by sharply reducing the federal funds rate by 3 percentage points between January and August; following the September 11 terrorist attacks, the Fed lowered the funds rate by 1.75 percentage points, for a total decline of 4.75 percentage points that year. This loosening of monetary policy was accompanied by markedly different performances across sectors. While sectors like housing and automobiles experienced a significant boom, IT spending remained flat during $2002 .{ }^{1}$

There are, of course, important reasons to care about the differences in the sectoral responses to monetary policy actions. For example, monetary policy will have a strong redistributive component if different sectors of the economy have different interest rate sensitivities. In this case, aggregate output stabilization via monetary policy would be achieved by inducing larger cyclical fluctuations in sectors that are more interest rate sensitive. Decoupling these sectors from the rest of the economy may induce some important redistributive effects when factors of production are sector specific. For instance, a monetary policy aimed at stabilizing aggregate output may fail to stabilize employment in response to a shock in a sector with low interest rate sensitivity when some aspects of human capital are sector-specific. A different reason to care about the heterogeneous effect of monetary policy is its implications about the effectiveness of monetary policy as a policy tool. The ability of an interest rate based monetary policy to jump-start the economy will depend on fraction of GDP associated with sectors that are highly sensitive to interest rates. We may expect then to find a link between output composition and the effectiveness of monetary policy, which may be especially important for policymakers.

These differential effects are important also because they raise issues about the role that monetary policy plays in the transmission of sectoral shocks. By changing

\footnotetext{
${ }^{1}$ Business forecasts predict only a small recovery for IT investment in 2003. Construction of new homes hit a 16-year high in December 2002; the volume of new cars was the largest in history during 2001.
} 
the level of the funds rate in response to a sectoral shock, monetary policy may either dampen or amplify the dynamic propagation of shocks across sectors. An appropriate understanding of the way that monetary policy interacts with sectoral shocks is also very important for policy design and has been largely unexplored in the literature.

This paper presents an empirical methodology based on the estimation of a structural vector autoregression (VAR) model to analyze the sectoral effects of monetary policy. This methodology allows us to compare the effects of monetary policy across sectors in terms of their delay, persistence, and sacrifice ratio. In addition, our methodology also allows us to determine how a sectoral shock is transmitted to the rest of the economy, both directly (through the interactions among sectors) and indirectly (through monetary policy).

The methodology we propose is an extension of the standard VAR models of monetary policy. Our specification decomposes aggregate GDP and includes all the components simultaneously in the VAR. The identification of this structural VAR is largely based on standard assumptions: (i) monetary policy responds contemporaneously only to the aggregate price index and GDP; (ii) all the components of GDP responds to monetary policy only with a lag. The only additional assumption we make is that the only source of contemporaneous comovement across sectors is the presence of correlated innovations. ${ }^{2}$ This assumption allows us to solve the problem in the degrees of freedom that arises in the unrestricted estimation.

We apply our methodology to U.S. data. We decompose GDP into seven componentsdurables consumption, nondurables consumption, services consumption, residential investment, investment in structures, equipment and software investment, and a residual-and characterize the response of each component to a monetary policy shock. Our results show that, even at this level of aggregation, there are considerable differences across components in response to monetary policy. In particular, we find that durables consumption, nondurables consumption, and residential investment have the largest response to monetary policy, that equipment and software investment has a mild response, and that, as in other studies (Bernanke and Gertler (1995)), investment in structures has no response.

We also find that a shock to equipment and software investment generates a

\footnotetext{
${ }^{2}$ The assumption that there is no contemporaneous relation across sectors has however been implicitly present in papers that study the sectoral effects of monetary policy by looking at one sector at a time (Bernanke and Gertler (1995), Barth and Ramey (2001), Rigobon and Sacks (1998)). In contrast to our approach, these papers do not assume any correlation among sectoral perturbations.
} 
significant effect on aggregate GDP. However, its effect on durables consumption, nondurables consumption, and residential investment is brief because of the countervailing effect of the automatic monetary policy response induced by the shock. Moreover, we find that a monetary policy shock aimed at smoothing the shock to equipment and software investment will generate a significant boom in the rest of the economy, especially in residential investment and durables consumption.

Overall, the simulated pattern of responses is remarkably similar to the evolution of the U.S. economy after the high-tech crisis, both qualitatively and quantitatively, which highlights the usefulness of our methodology for analyzing monetary policy.

This paper is part of the vast empirical literature on the effects of monetary policy. Our methodology builds on the structural VAR approach used in this context by Bernanke and Blinder (1992), Bernanke and Mihov (1998), Christiano and Eichenbaum (1992), and Christiano et al. (1996b,a), among others. We extend this methodology to explore the sectoral effects of monetary policy and to consider the transmission of sectoral shocks. The sectoral effects of monetary policy have been previously studied by Bernanke and Gertler (1995) and Barth and Ramey (2001), among others. Our paper extends this literature in several dimensions. First, these papers rely on the standard recursiveness assumption for identification and typically add a subset of sectors to an aggregate VAR to avoid getting into a degrees of freedom problem. ${ }^{3}$ The problem with this approach is that the whole VAR is re-estimated for each subset of sectors added to the specification. ${ }^{4}$ Therefore, the structural parameters of the monetary policy rule are allowed to change across specifications. ${ }^{5}$ Second, by analyzing all sectors simultaneously we can study how shocks to particular sectors impact other sectors and the rest of the economy. In contrast, most of the papers in the literature study one sector at a time using the recursiveness assumption.

\footnotetext{
${ }^{3}$ Under the recursiveness assumption, the number of structural parameters grows quadratically with the number of sectors in the VAR. So, adding one sector requires a significant increase in the number of observations.

${ }^{4}$ In this sense, the approach lacks internal consistency. Some of the papers in this literature (Barth and Ramey (2001), Dedola and Lippi (2000)) have an additional consistency problem: they add each sector at the bottom of the aggregate VAR. This boils down to assume that monetary policy affects aggregate GDP only with a lag, but affects contemporaneously each of its components.

${ }^{5}$ Rigobon and Sacks (1998) partially addressed the issue of the stability of the parameters by using a two step procedure that first estimates the structural innovations from an aggregate VAR and then feeds these innovations as exogenous variables in the dynamic specification of sectoral output. Even though this approach maintains the parameters of the monetary policy response stable across sectors, it is less efficient than our procedure, and it also does not permit to analyze the transmission of sectoral shocks.
} 
Therefore, they cannot be used to analyze the transmission of sectoral shocks.

The rest of the paper is structured as follows. Section 2 describes the empirical methodology and the identification assumptions. Section 3 documents the sectoral effects of monetary policy in the U.S.. In section 4, we use our model to analyze the effect of a shock to equipment and software investment on the rest of the U.S. economy and to determine the consequences of a monetary policy aimed at stabilizing that shock. Section 5 concludes.

\section{Empirical methodology}

\subsection{Standard VAR Analysis of Monetary Policy}

We use a VAR model to estimate the sectoral effects of monetary policy. Sims (1980) pioneered the use of VAR to identify exogenous shocks to monetary policy and their effect on different economic aggregates and Bernanke and Blinder (1992) and Christiano and Eichenbaum (1992), among others developed it further. The standard model in the literature can be represented by the following structural VAR:

$$
A_{0} X_{t}=\sum_{i=1}^{q} A_{i} X_{t-i}+\varepsilon_{t}
$$

where $X_{t}=\left(Z_{t}, S_{t}\right)^{\prime}, S_{t}$ is the instrument of the monetary authority, $Z_{t}$ are the variables in the monetary authority's information set, and $q$ is a non-negative integer. This specification assumes that the monetary authority follows a policy rule that is linear on the variables in $Z_{t}$ and their lags. In addition, it is assumed that the perturbations $\varepsilon_{t}$ have the following properties:

$$
E\left[\varepsilon_{t}\right]=0 ; E\left[\varepsilon_{t} \varepsilon_{\tau}^{\prime}\right]=\left\{\begin{array}{cc}
D & \tau=t \\
0 & \text { otherwise }
\end{array} .\right.
$$

The estimation of this model is usually performed in two steps. First, the parameters of the corresponding reduced form VAR are estimated,

$$
X_{t}=\sum_{i=1}^{q} B_{i} X_{t-i}+u_{t}
$$


and second, the structural parameters $\left(A_{i}\right.$ and $\left.D\right)$ are recovered by making a series of identification assumptions. The most widely used identification assumption in the literature is the "recursiveness assumption." This approach corresponds to assuming that the structural errors $\left(\varepsilon_{t}\right)$ are orthogonal $(D=I)$ and the matrix summarizing the contemporaneous relations between the variables in the VAR $\left(A_{0}\right)$ is block diagonal. That is, it is assumed that the variables in $X_{t}$ can be arranged as $X_{t}=\left(Z_{1 t}^{\prime}, S_{t}, Z_{2 t}^{\prime}\right)^{\prime}$ and

$$
A_{0}=\left[\begin{array}{ccc}
a_{11} & 0 & 0 \\
a_{21} & a_{22} & 0 \\
a_{31} & a_{32} & a_{33}
\end{array}\right]
$$

where the dimensions of the $a_{i j}$ blocks of the matrix $A_{0}$ are determined by the dimensions of $Z_{1}, S$, and $Z_{2}$.

Intuitively, the recursiveness assumption corresponds to assuming that, under the monetary policy rule, the contemporaneous values of the variables in $Z_{1 t}$ elicit an immediate change in the monetary policy instrument, but these variables themselves respond to the instrument only with a lag. Analogously, the values of the variables in $Z_{2 t}$ elicit a lagged change in the monetary policy instrument, but these variables themselves respond to the instrument change immediately.

It can be demonstrated that the recursivness assumption is sufficient to identify the column of $A_{0}$ associated wuth the monetary policy instrument; thus, it is also sufficient to determine the response of all the variabels to a monetary policy shock; however, it is not sufficient to determine the response of all the variables to any other structural shock, because the block diagonal structure of $A_{0}$ makes the equations in the upper and lower blocks of the matrix indistinguishable.

The set of variables included in the monetary policy rule $\left(Z_{t}\right)$ varies considerably in the literature. The simplest model considers a measure of activity (usually GDP) and a measure of the price level (usually the CPI or the GDP deflator). ${ }^{6}$ There are also differences regarding the variable to include as the monetary policy instrument. While some papers argue in favor of using the federal funds rate (Bernanke and Blinder (1992), Bernanke and Mihov (1998)), others have argued in favor of using the level of non-borrowed reserves (Christiano and Eichenbaum (1992)) or the ratio of non-borrowed to total reserves (Strongin (1995)). Regardless of the monetary policy

\footnotetext{
${ }^{6}$ Most papers also include a measure of commodity prices to account for the "price puzzle", which we discuss further below (see Christiano et al. (1999)).
} 
instrument considered, the literature typically assumes that the monetary rule calls for a response to contemporaneous values of the measures of activity and prices, but these respond to the monetary policy instrument only with a lag. ${ }^{7}$

This methodology has proved to be extremely useful in understanding the dynamics of a monetary economy, but it is not exempt from criticism. In particular, the zero-restrictions implicit in the block diagonal structure of $A_{0}$, which are crucial for identifying the monetary policy innovations, are arbitrary. ${ }^{8}$ We do not address this criticism in this paper, as we are mainly concerned with understanding the sectoral aspects of monetary policy.

In summary, the standard way of determining the effects of monetary policy in the literature is to estimate a reduced form VAR model including at least a measure of activity and the price level, and a monetary policy instrument. The recursiveness assumption is then used to identify the relevant structural parameters. In the next section we show how, with minor modifications, this simple framework can be extended to analyzing the sectoral effects of monetary policy and the interactions among sectors.

\subsection{A sectoral model of monetary policy}

Our approach to estimating the sectoral effects of monetary policy is a simple extension of the standard model in the literature. We assume that the monetary policy instrument $\left(F_{t}\right)$ responds only to activity $\left(Y_{t}\right)$ and prices $\left(P_{t}\right)$, and decompose the measure of activity $\left(Y_{t}\right)$ into $N$ different components, so $X_{t}=\left(Y_{1 t}, \ldots, Y_{N t}, P_{t}, F_{t}\right)$. If we were to identify this VAR through the recursiveness assumption we would have to assume that:

$$
A_{0}=\left[\begin{array}{ccc}
A_{11} & A_{12} & 0 \\
A_{21} & a_{22} & 0 \\
A_{31} & a_{32} & a_{33}
\end{array}\right],
$$

where the $A_{i j}$ terms are the natural expansions of the $a_{i j}$ elements to $N$ variables. ${ }^{9}$

This identification would allow us to recover the structural parameters from the

\footnotetext{
${ }^{7}$ Bernanke and Blinder (1992) and Christiano et al. (1996b) consider also the possibility that the monetary policy instrument responds only with a lag to activity and prices, which respond contemporaneously to the monetary policy shock.

${ }^{8}$ See Faust (1998), Faust et al. (2003), Rudebusch (1998), and Uhlig (1999).

${ }^{9}$ For example, $a_{32}$ is an scalar that contains the response of the interest rate to changes in the price level. Simmilarly, $A_{31}$ is a $1 \times N$ vector containing the effect of each sector on the interest rate.
} 
reduced form parameters. However, disaggregating the measure of activity into its components would lead us very quickly into a degrees of freedom problem. Indeed, this model has $(N+2)^{2}(q+1)+1$ parameters, ${ }^{10}$ so we would need at least $(N+2)(q+1)+1$ observations of each variable. Assuming that the frequency of the data is equal to the number of lags, this implies that we would need at least $T=(N+2)+(N+3) / q$ years of data in order to estimate the parameters. For example, if we were using 7 sectors and quarterly data, 12 years of data would leave us with zero degrees of freedom.

As mentioned in the previous section, an additional problem with using the recursiveness assumption to estimate the sectoral model is that it can only identify the sectoral effects of monetary policy, but it cannot identify the effects of a sectoral shock on the rest of the economy. Identifying the effect of these shocks requires assumptions on the coefficients of $A_{0}$ beyond the block diagonal structure. In particular, it requires that enough conditions are imposed on the coefficients of $A_{11}$ so that each equation can be individually identified.

For these reasons, we depart from the recursiveness assumption and use an identification scheme that combines some elements of the recursiveness assumption with additional assumptions from the simultaneous equations view of identification. In particular, we assume that (i) the price level index relevant for monetary policy depends only on aggregate activity, (ii) the monetary policy rule is a function only of aggregate activity and the price level index, (iii) the structural innovations to different sectors are correlated, and (iv) each sector's activity affects other sectors only with a lag. These assumptions impose the following structure on $A_{0}$ and $D$ :

$$
\begin{gathered}
A_{0}=\left[\begin{array}{ccc}
I_{N} & A_{12} & 0 \\
\alpha e_{N} & 1 & 0 \\
\beta e_{N} & \beta_{p} & 1
\end{array}\right], \\
D=\left[\begin{array}{ccc}
\Sigma & 0 & 0 \\
0 & \sigma_{p}^{2} & 0 \\
0 & 0 & \sigma_{F}^{2}
\end{array}\right],
\end{gathered}
$$

where $e_{N}$ is a row vector of ones of dimension $N$ and $\Sigma$ is a $N \mathrm{x} N$ matrix. Assumptions (i) and (ii) are captured by imposing a common coefficient for all sectors in the

\footnotetext{
${ }^{10}$ Under the recursiveness assumption, $A_{0}$ has $(N+2)(N+1)+1$ parameters, $A_{i} i=1, \ldots, q$ has $(N+2)^{2}$, and $D$ has $(N+2)$ variances.
} 
rows of $A_{0}$ associated with the price index and monetary policy rule ( $\alpha$ and $\beta$, respectively). These assumptions are implicit in the papers that estimate the effects of monetary policy using aggregate data (e.g. Bernanke and Blinder (1992), Christiano and Eichenbaum (1992)), and they help to reduce the degrees of freedom problem. They boil down to assuming that the Taylor rule followed by the monetary authority depends only on aggregate indicators. Assumptions (iii) and (iv) are non-standard and require further discussion. As previously mentioned, the standard recursiveness approach would have $A_{11}$ unrestricted and $\Sigma$ diagonal, so the sectoral shocks would be completely idiosyncratic, and any contemporaneous comovement across sectors would be due to the simultaneous relations captured in $A_{11}$. Instead, our identification scheme assumes that all contemporaneous comovement among sectors is due to the correlation among their structural innovations.

Before proceeding further, note that assumptions (iii)-(iv) are not necessary to identify the sectoral effects of monetary policy. What we get from assumptions (iii) and (iv) is a reduction in the number of structural parameters to be estimated and, most importantly, the possibility of analyzing the effects of a sectoral shock. These benefits come at the cost of imposing symmetry in the contemporaneous relations across sectors and having correlated structural sectoral shocks. So, a possible criticism to our approach is that we make assumptions to identify the effect of sectoral shocks, but we obtain a model in which these shocks are not truly independent. In order to address this criticism, we also estimate our model imposing some additional structure in the covariance matrix that introduces independent sectoral shocks. In particular, we also consider the case in which sectoral shocks are orthogonal and all the correlation among sectors is due to an aggregate shock. This corresponds to assuming that:

$$
\begin{aligned}
\varepsilon_{t} & =\Gamma z_{t}+\mu_{t} \\
E\left[z_{t}\right] & =0, E\left[z_{t}^{2}\right]=\sigma_{z}^{2} \\
E\left[\mu_{t}\right] & =0, E\left[\mu_{t} \mu_{t}^{\prime}\right]=\Omega \text { diagonal }
\end{aligned}
$$

where $\Gamma=\left(\gamma_{1}, \ldots, \gamma_{N}, 0,0\right)^{\prime}$.

Of course, this is not the first attempt to estimate the sectoral effects of monetary policy. The main contribution of this paper is our identification approach, which allows us to identify the sectoral effects of monetary policy and the transmission of sectoral shocks simultaneously, making very few additional assumptions beyond the 
standard VAR models in the literature. The approach typically followed in the literature on the sectoral effects of monetary policy (e.g., Barth and Ramey (2001), Dedola and Lippi (2000)) is to estimate a structural VAR that includes aggregate variables (GDP, a price index, and a commodity price index), the monetary policy instrument (usually the federal funds rate), and an index of industrial activity (typically an industrial production index)-in that order-and that identifies the effects of monetary policy using the recursiveness assumption. That is, they assume $X_{t}=\left(Y_{t}, P_{t}, C P_{t}, F_{t}, Y_{i t}\right)^{\prime}$. Under the standard recursiveness assumption, the ordering of this VAR assumes that the monetary policy rule reacts contemporaneously to the values of $Y_{t}, P_{t}$, and $C P_{t}$, but those variables react to the monetary policy instrument only with a lag. It also assumes that monetary policy responds to the activity of sector $i$ with a lag, but that sector $i$ is affected contemporaneously by the monetary policy instrument. It is clear that these two sets of assumptions are mutually inconsistent: we cannot assume simultaneously that monetary policy does not affect any component of aggregate activity contemporaneously, but it does affect contemporaneously the sum of them. More importantly, by estimating a different VAR for each sector, these papers permit variation both on the parameters of the monetary policy rule and on the information set relevant for the monetary policy response. This affects the model's ability to compare the effects of monetary policy across sectors. In contrast, we provide a methodological framework that estimates a common monetary policy rule across sectors, which allows us to perform meaningful comparisons, and it is based on a clear set of identification assumptions that can be subject to debate and robustness checks.

\section{Sectoral effects of monetary policy in the U.S.}

This section presents the results obtained by applying our methodology to the estimation of the sectoral effects of monetary policy in the U.S.. We decompose U.S. GDP into seven components: durables consumption $(C D U R)$, nondurables consumption $(C N D U R)$, services consumption $(C S E R)$, residential investment (IRES), equipment and software investment (IEQUIP), structures investment (ISTRUC), and a residual compressing government expenditure, inventory investment, and net exports $\left(R E S T_{t}\right)$. We use the Consumer Price Index $(C P I)$ as a measure of the price level and the federal funds rate $(F F R)$ as the monetary policy instrument. So, our vector $X_{t}$ 
corresponds to $\left(C D U R_{t}, C N D U R_{t}, C S E R_{t}, I R E S_{t}, I E Q U I P_{t}, I S T R U C_{t}, R E S T_{t}\right.$, $\left.C P I_{t}, F F R_{t}\right)^{\prime}$, and we estimate the structural parameters of (3) and (4) by Maximum Likelihood ${ }^{11}$ using quarterly data for the period 1955:1-2002:3. ${ }^{12}$ We first present the results obtained for aggregate activity (the sum of the sectoral effects) and compare them with previous results in the literature as a benchmark for our methodology. Then we turn to the sectoral results.

\subsection{An aggregate benchmark}

In an aggregate model of monetary policy with GDP, prices, and the federal funds rate $(F F R)$ in the VAR, the matrix $A_{0}$ has three relevant parameters: (i) the effect of output on prices, (ii) the automatic response of the $F F R$ to output, and (iii) the automatic response of the FFR to prices. As our methodology assumes that the contemporaneous Taylor rule followed by the monetary authority responds only to aggregate quantities, we directly estimate each parameter $\left(\alpha, \beta\right.$, and $\beta_{p}$ in equation (3) respectively). The coefficients estimated for these parameters are reported in Table 1 . The results are consistent with a policy rule aimed at stabilizing output and prices. The coefficients of $\beta$ and $\beta_{p}$ are negative, which implies that the monetary authority tends to raise the FFR in response to an increase in output or prices. The three coefficients are statistically significant at conventional levels.

The coefficient obtained for $\alpha$ is somewhat puzzling because it implies that prices fall contemporaneously in response to an increase in output. There are two possible explanations for this result. First, it is possible that the output innovations are positive productivity shocks, which are associated with price reductions. Second, it is possible that the result reflects the well known "price puzzle"-where an increase in commodity prices, which we do not control for, tends to increase the aggregate price and to reduce output. ${ }^{13}$

\footnotetext{
${ }^{11}$ The parameters can also be estimated by a two-step procedure (see Raddatz and Rigobon (2003a)). The first step consists of estimating the reduced form parameters, and the second step recovers the structural parameters using the Generalized Method of Moments (GMM). The results obtained with both procedures are remarkably similar. The main difference is that, consistent with the larger degrees of freedom of the ML estimation, the main structural coefficients $\left(A_{0}\right.$ and $\left.\Sigma\right)$ are more precisely estimated.

${ }^{12}$ The data on the GDP components were obtained from the Bureau of Economic Analysis. Data on the $C P I$ and the FFR were obtained from the website of the Federal Reserve Bank of St. Louis.

${ }^{13}$ See (Sims (1992)) for a discussion of the "price puzzle". We do not include a commodity price index in order to focus on the sectoral results.
} 
Table 1: Coefficients of contemporaneous effects

\begin{tabular}{ccc}
\hline \hline \multicolumn{3}{c}{ Parameters } \\
$\widehat{\alpha}$ & $\widehat{\beta}$ & $\widehat{\beta}_{p}$ \\
\hline \hline & & \\
0.145 & -0.238 & -0.689 \\
$(0.049)$ & $(0.140)$ & $(0.205)$ \\
& & \\
\hline \hline
\end{tabular}

Note: Standard errors in parenthesis

Indeed, the impulse response functions reported in Figure 1 clearly show the "price puzzle." They measure the effect of a one standard deviation shock to the FFR on aggregate GDP, which is computed by aggregating the individual sectoral responses to the monetary policy innovation.

The monetary policy shock-corresponding to an 80 basis points rise in the FFRinduces an immediate response from aggregate GDP, which contracts for about eight quarters before starting to return to its baseline level. ${ }^{14}$ Prices initially increase but start to fall around the fifth quarter. The main message from this exercise is that our estimations of the size of the shock and the responses of the aggregate variables are qualitatively and quantitatively consistent with previous estimations from VAR models that used aggregate GDP (see Bernanke and Gertler (1995), Christiano et al. (1999)).

\subsection{What do the residuals look like?}

In the empirical literature analyzing monetary policy using the structural VAR approach, the estimated structural residuals of the monetary policy equation are interpreted as monetary policy shocks. Similarly, in our approach the structural innovations to a sector's equation are interpreted as (non-orthogonal) shocks to that sector. In this section, we describe some characteristics of the structural residuals and compare them with previous estimations of the innovations to monetary policy and recent events in the U.S. economy. This comparison allows us to observe whether our model is capturing some salient features of the data.

\footnotetext{
${ }^{14}$ The magnitudes are expressed in percentage points. As the GDP series is normalized by the average real GDP in the last five years, the impulse responses correspond to percentage deviations from that baseline
} 


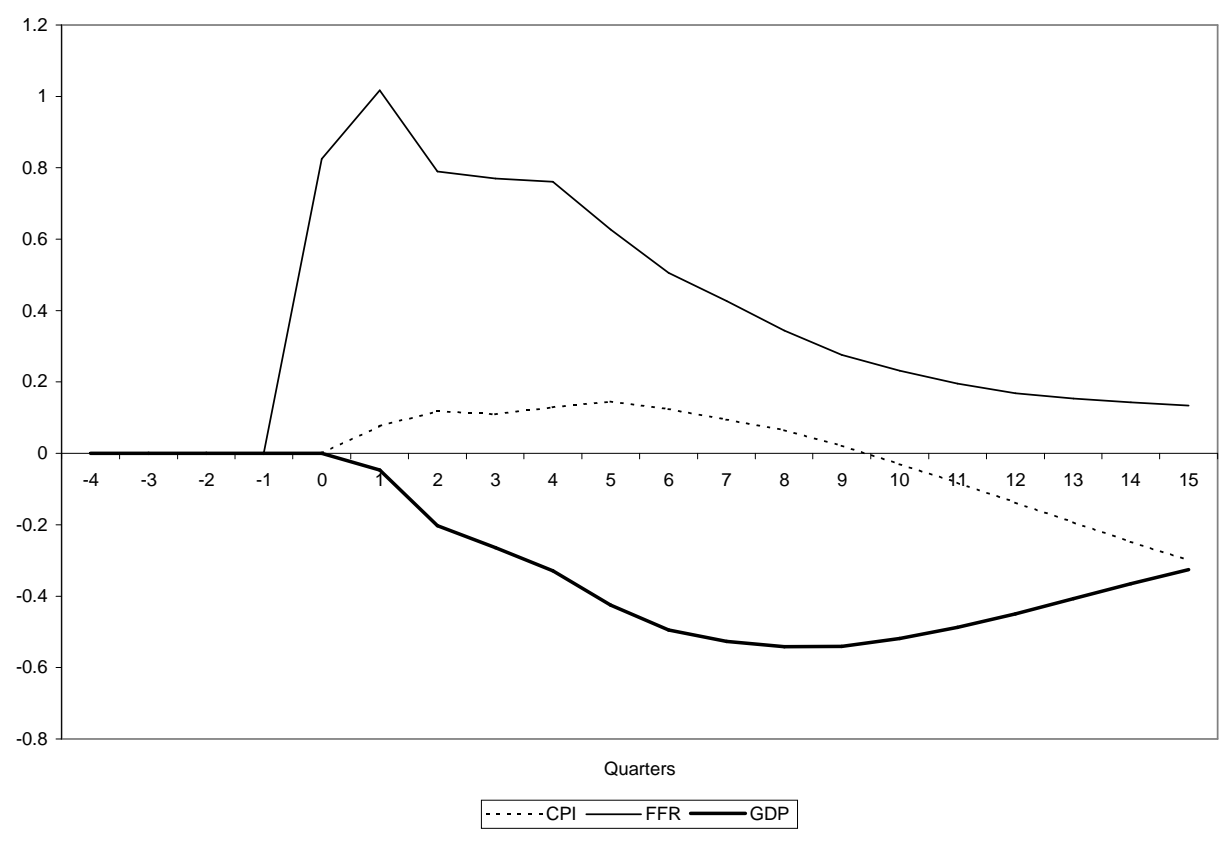

Figure 1: Effect of a shock to FFR on GDP, CPI, and FFR

\subsubsection{Comparing the policy shock measure}

Figure 2 compares the policy shock measure obtained in our estimations with two previous measures of monetary policy shocks in the literature: the Romer episodes (Romer and Romer (1989)) and one of the measures obtained by Christiano et al. (1996b). ${ }^{15}$ We find a strong correlation between our measure and the Christiano, et al., measure. This is not really surprising, considering that our identification assumptions regarding the monetary policy rule are very similar to theirs. ${ }^{16}$ The main difference between our specification and theirs is that Christiano, et al. assume that the monetary authority also responds to the level of total and non-borrowed reserves (though only with a lag). This seems not to be a first order issue, given the high correlation between the two series of structural residuals.

The relation between our policy shock measures and the Romer episodes is also surprisingly good. With the exception of the third quarter of 1978-a period in which

\footnotetext{
${ }^{15}$ For comparability purposes, we use the Christiano, et al. specification with the federal funds rate as the policy instrument, no commodity prices, and benchmark identification (see Christiano et al. (1996b), p. 43). As they emphasize, all their measures are qualitatively similar.

${ }^{16}$ As noted above, the restrictions imposed on the parameters force the monetary policy rule to respond only to aggregate GDP and price levels, not to their composition. This is exactly what Christiano, et al. implicitly assume by using aggregate data.
} 


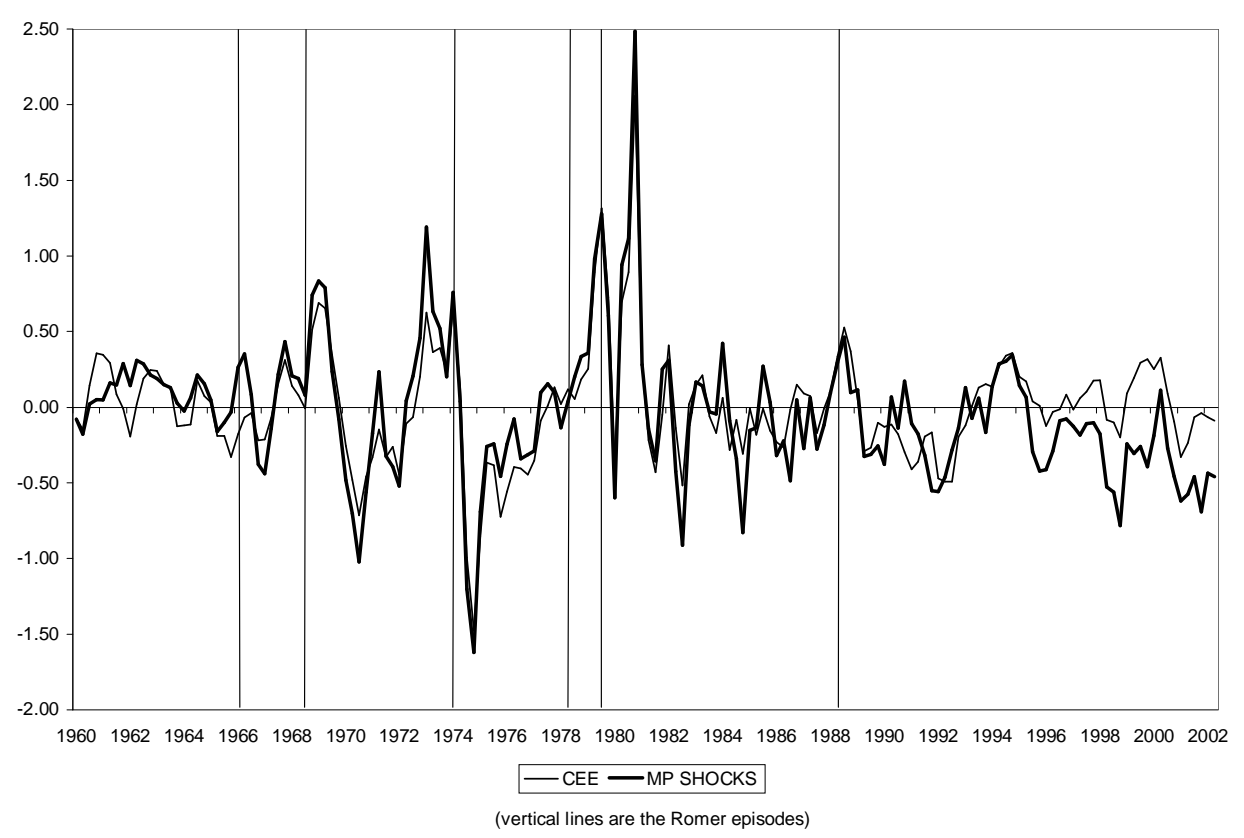

Figure 2: Measures of monetary policy shocks

the Romers report a tightening of monetary policy-the Romer episodes are clearly associated with the presence of positive monetary policy shocks.

In summary, the monetary policy shocks estimated from the structural residuals of our model seem to conform well with the results of previous studies.

\subsubsection{The High-Tech crisis and the 1990-1991 recession}

In the late 1990's IT related businesses expanded immensely. The NASDAQ composite index, which was closely associated with the "new economy", reached a peak in February 2000 at almost 5000 points, more than three times larger than its 1997 level of about 1500. All this hype came to a sudden stop in late 2000 and early 2001. Between August 2000 and August 2001 the NASDAQ fell 60\%, from 4200 to 1800 points. At the same time, after growing at $16 \%$ during 2000 , IT investment fell by $6 \%$ in 2001 . The onset of crisis on the high-tech sector marked the end of the late 1990's expansion in the U.S. and the beginning of the recent recession. Our methodology clearly captures this episode. Our estimated structural residuals show that equipment and software investment experiences two large negative shocks in the first two quarters of 2001-corresponding to 2.6 and 3.9 standard deviations respec- 


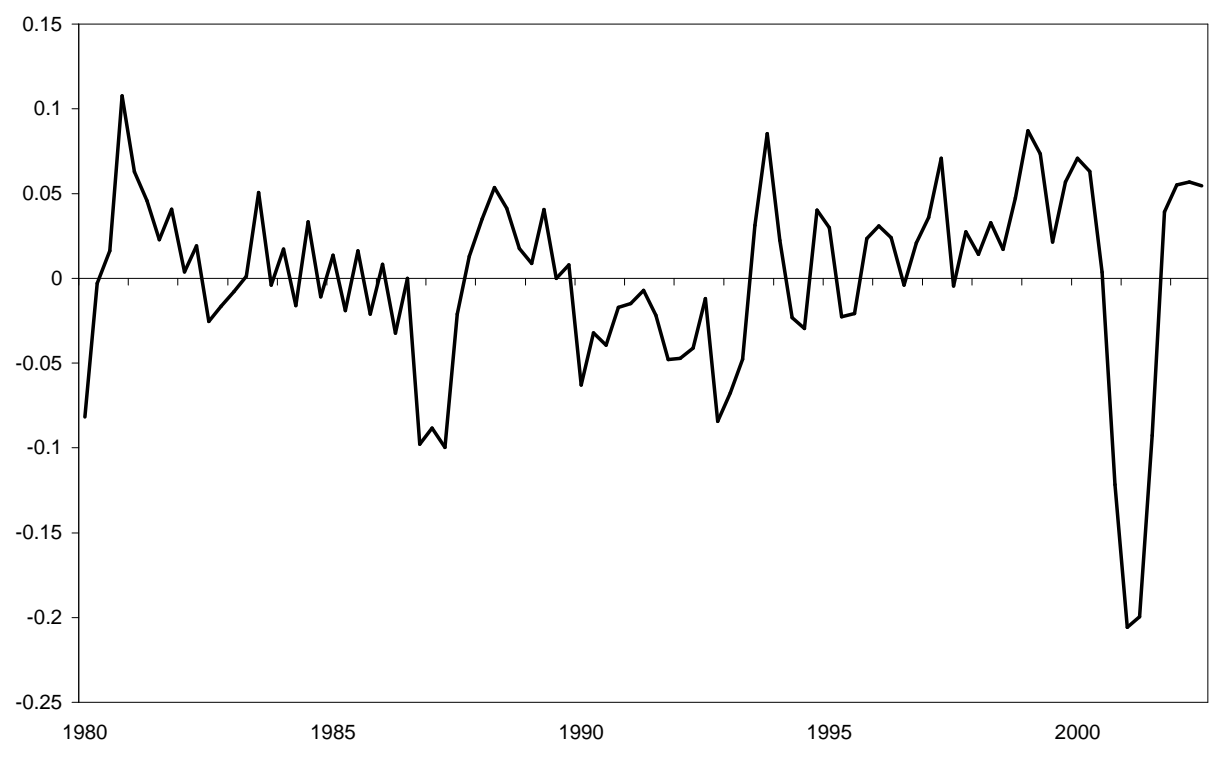

Figure 3: Shocks to Equipment and Software Investment

tively. ${ }^{17}$ This situation is depicted in Figure 3, which shows the structural residuals of the equipment and software investment series. ${ }^{18}$ Note that these shocks are larger than any other shocks previously experienced by this sector. Additionally, note that our residuals also show consecutive positive innovations during the 90's reflecting the large boom in that sector during that time.

Our structural residuals also seem to capture the events of the 1990-1991 recession. Between the second quarter of 1990 and the second quarter of 1991 (the official peak and trough dates according to the NBER) we observe large negative shocks to residential investment ( 2 std. dev.), services consumption ( 2.5 std. dev.), and durables consumption (1.8 std. dev). The situation is summarized in Figure 4, which shows that this was clearly an episode of constrained aggregate demand. Overall, these findings are consistent with the general view that the 1990-1991 recession was largely associated with a crisis in consumer confidence.

\footnotetext{
${ }^{17}$ Shocks of this magnitude are rare, with only four episodes of shocks larger than 2.5 standard deviations observed within sample ( $2 \%$ of observations). In other words, the distribution of the structural residuals has no particularly fat tails (though they are fatter than the normal case).

${ }^{18} \mathrm{By}$ construction, the structural residuals are serially uncorrelated, so the series are very noisy. Following Christiano et al. (1996b), we report the centered three quarter moving average of the residuals.
} 


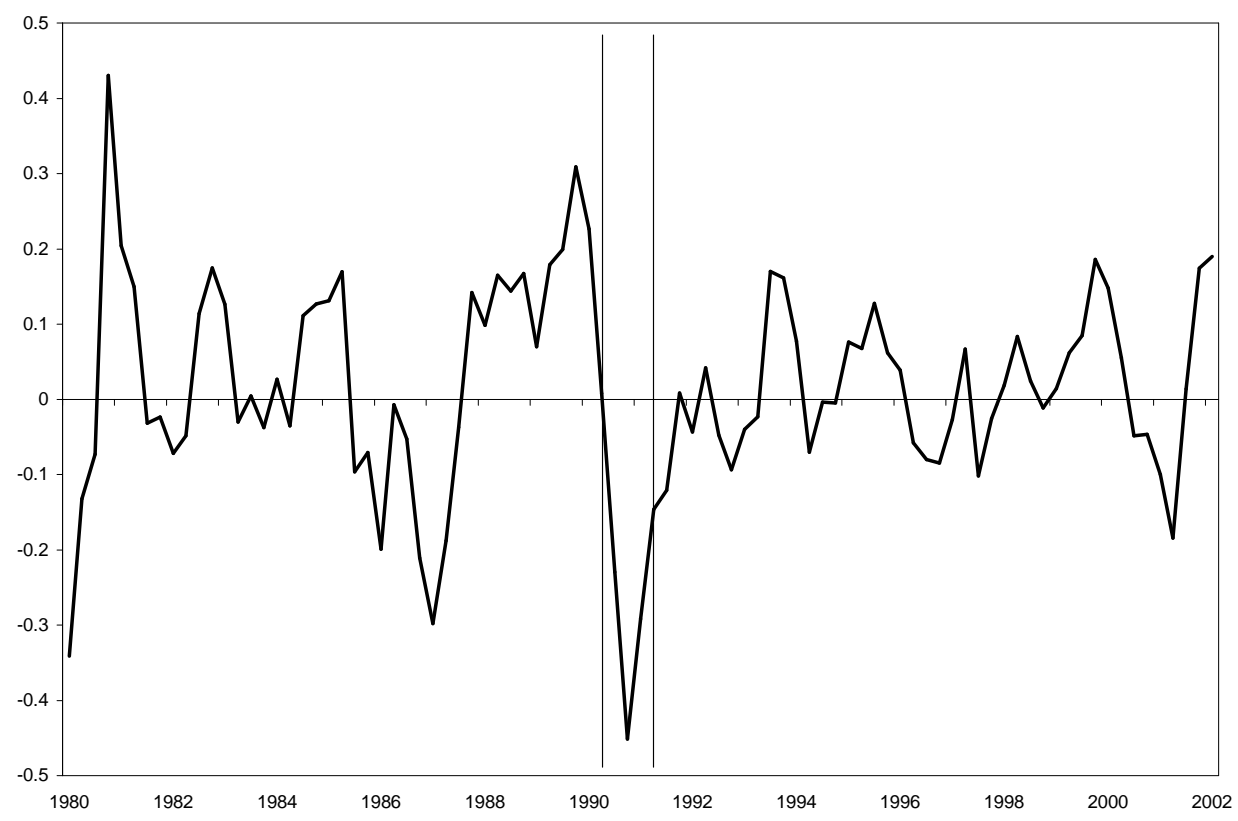

Figure 4: Sum of shocks to Durables, Non-durables, Services, and Residential Investment

\subsubsection{September 11 and the Accounting Scandals}

The economy was subject to two other important shocks at the end of 2001 and the beginning of 2002: the September 11 attacks and the accounting scandals after the collapse of Enron. Because our data are quarterly, it is impossible for us to disentangle these two shocks, but we can evaluate their overall effect.

As can be seen in Figure 5, most sectors were recovering from the high-tech crisis when these two shocks struck. Most sectors show positive innovations at the end of 2001 that turn notably negative for the first quarter of 2002 and beyond.

\subsection{Sectoral sacrifice ratios to monetary policy tightening.}

Figure 6 shows the impulse responses functions of the different GDP components to a one standard deviation contractionary shock to the federal funds rate. The figure also displays the $90 \%$ confidence bands associated to the impulse response functions. ${ }^{19}$

\footnotetext{
${ }^{19}$ The confidence bands were estimated by a bootstrap procedure which is more conservative than the standard approach in the literature, so they tend to be wider. The procedure is described in the appendix.
} 

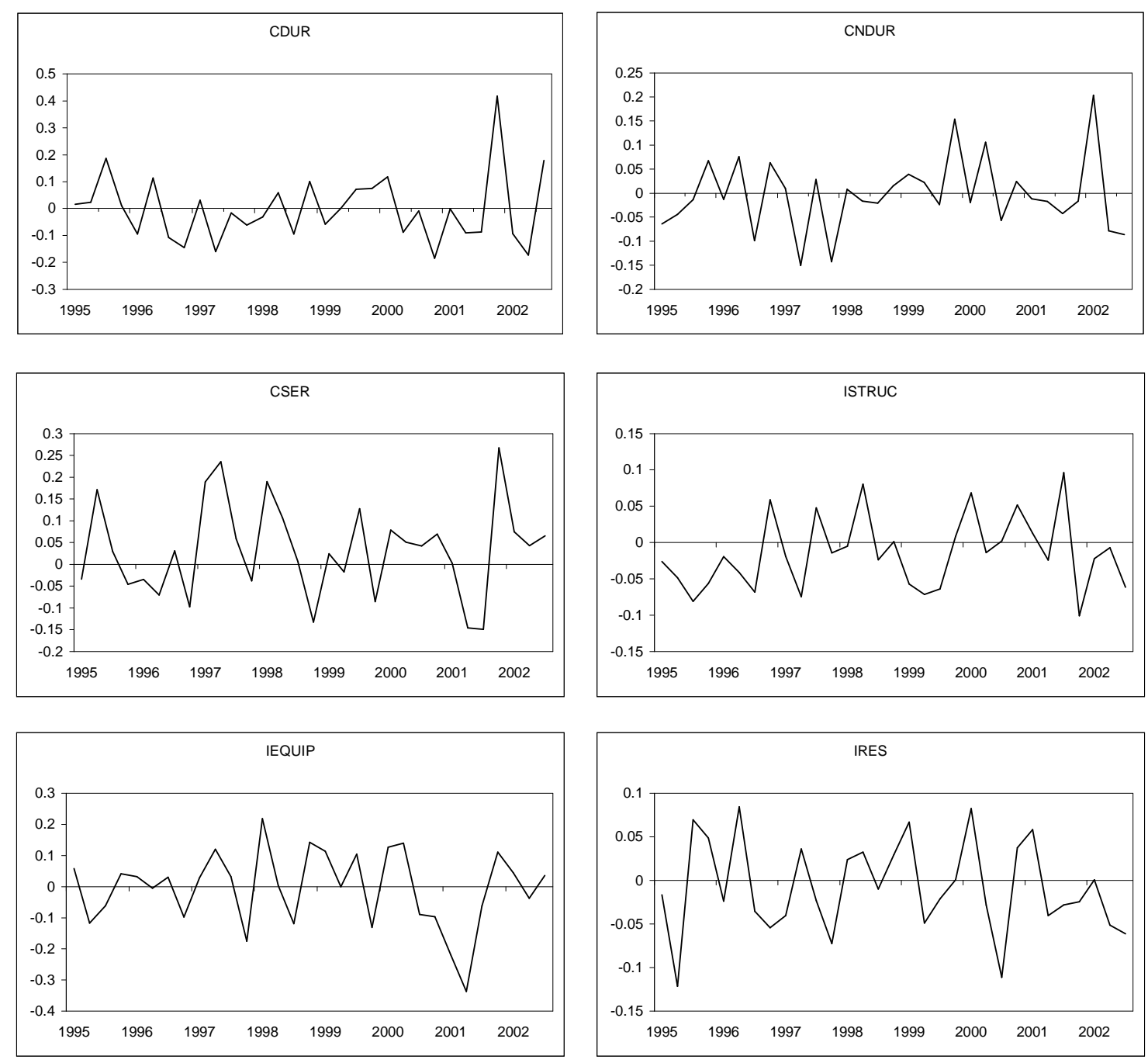

Figure 5: Sectoral Residuals 
The monetary policy shock has a significant and lasting effect in four sectors: durables consumption, nondurables consumption, services consumption, and residential investment. A minor effect is observed in equipment and software investment. As previously found in the literature (Bernanke and Gertler (1995)), structures investment is largely unaffected.

The lag in the monetary policy effect is roughly similar across sectors, but some interesting differences are observed. The trough of the response of GDP to the shock is achieved in eight quarters. Thus, the maximum effect of monetary policy is achieved two years after a shock. This magnitude is similar across those sectors in which monetary policy has a statistically significant effect: the maximum effect of the shock in durables consumption, services consumption, and residential investment is also experienced at the eighth quarter. The only deviation observed is for nondurables consumption, with a trough in the twelfth quarter. Some differences in the lags across these sectors are also observed when we compare the first period in which their response to the monetary policy shock is statistically different from zero. According to this measure, the lag of the monetary policy effect is shorter in residential investment and services consumption than in durables consumption and nondurables consumption; while residential investment and services consumption respond almost immediately to the monetary policy shock, the shock has no effect on durables consumption and nondurables consumption until around the second quarter.

One of the sectors with the longest lagged response to monetary policy is equipment and software investment with a trough at the tenth quarter. This finding provides some evidence that equipment and software investment has a particularly slow response to monetary policy. Indeed, it is only around the eighth quarter that the effect of monetary policy is statistically different from zero for reasonable (although non-standard) confidence levels.

The impulse response functions also show that the monetary policy shock is highly persistent. According to the point estimators, GDP has still not returned to its baseline level after twenty quarters. This high persistence is also observed across sectors, where, with the exception of services consumption, none has returned to its baseline level after twenty quarters. A conservative measure of the persistence of monetary policy is given by the number of periods during which the effect of monetary policy is significantly different from zero at conventional levels. Using this measure we find that the persistence is about nine quarters for durables consumption, twelve 

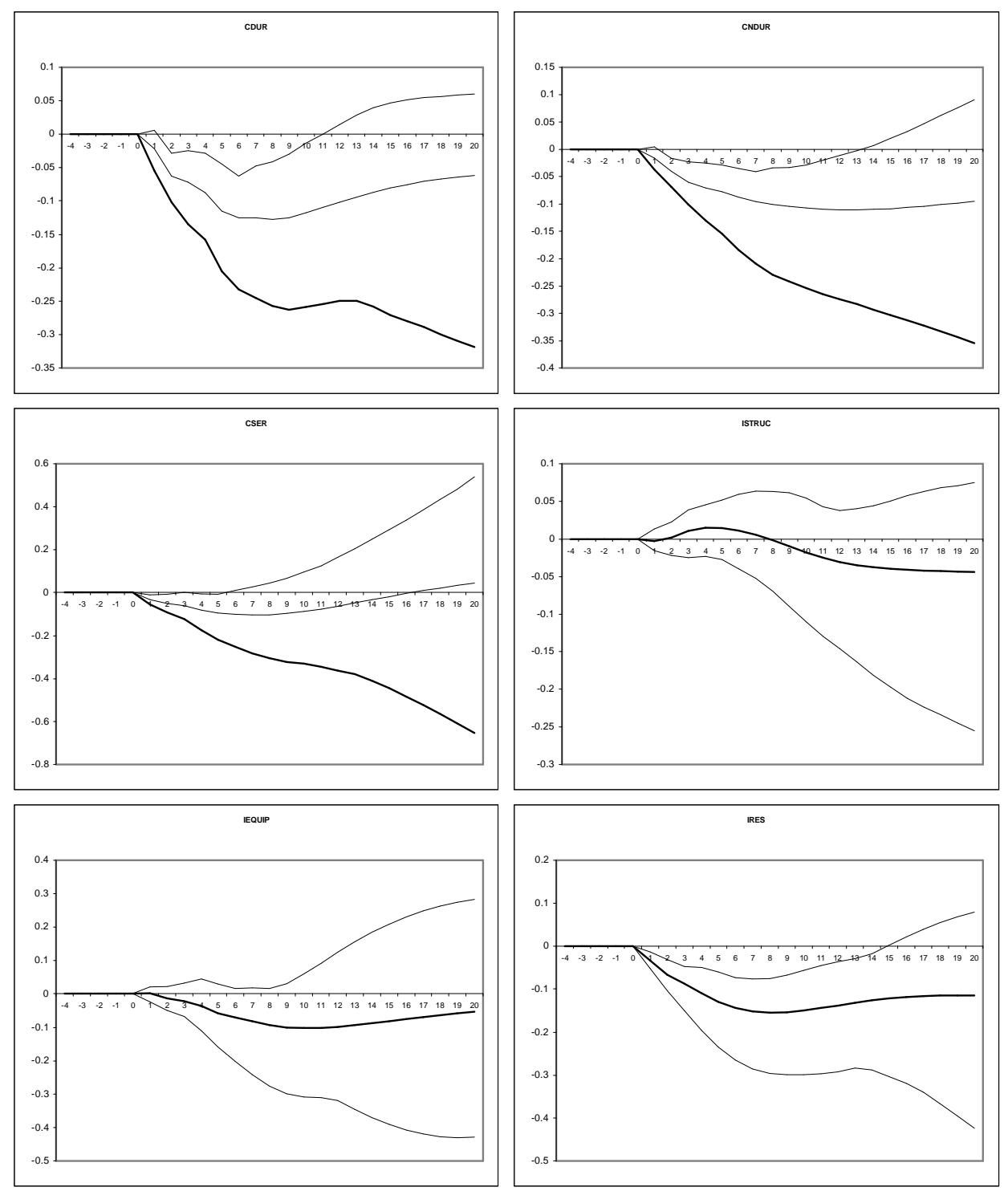

Figure 6: Sectoral effects of a monetary policy shock 


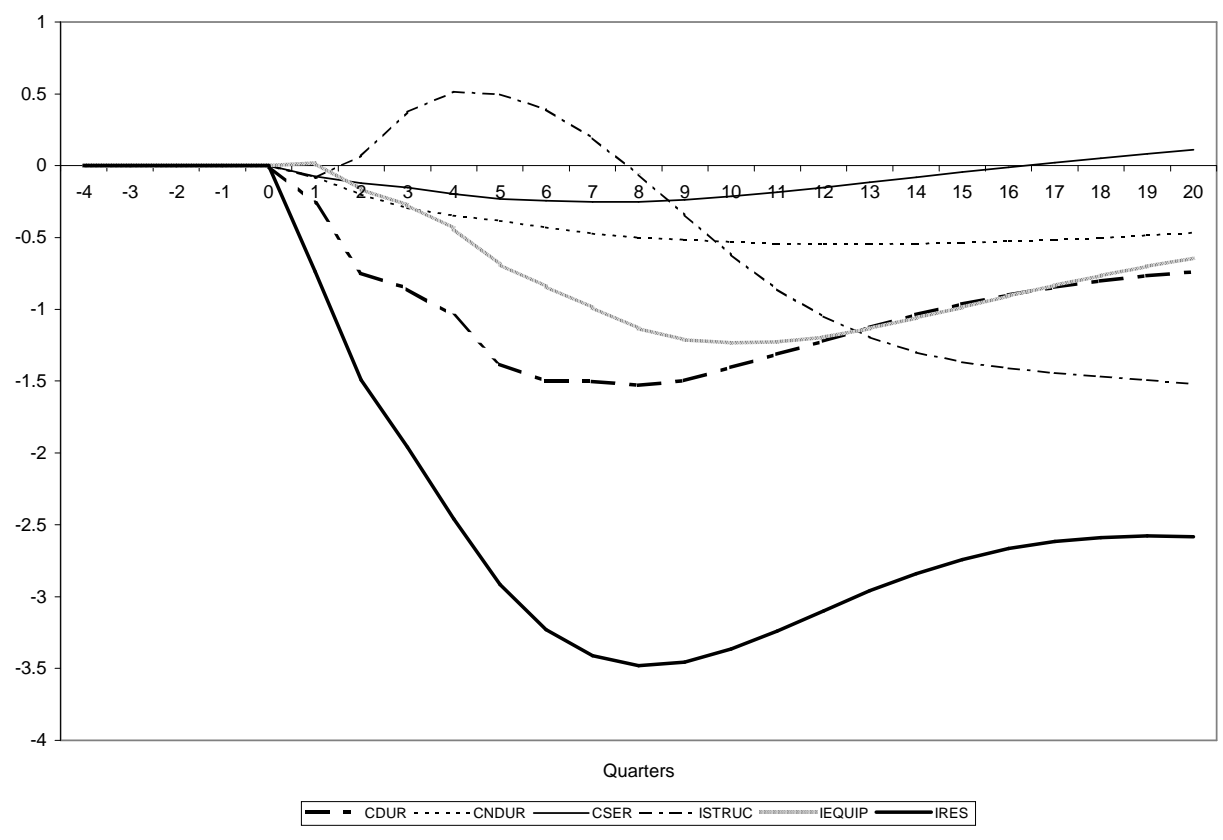

Figure 7: Sacrifice ratios (shock to FFR)

quarters for nondurables consumption, four quarters for services consumption, and fourteen quarters for residential investment. Under this measure, the persistence in equipment and software investment would be around two quarters.

A more interesting measure of the effect of monetary policy across different sectors is the sacrifice ratio, reported in Table 2. The ratios were computed using the point estimates and represent a measure of the output loss resulting from the monetary policy shock for each sector as a fraction of its baseline level. They correspond to the area between the $\mathrm{x}$ axis and the normalized impulse response function during the period between the monetary policy shock and the minimum of the quarter in which the series returns to its baseline level and twenty quarters. The normalized impulse responses for the different sectors are reported in Figure 7. We observe in Table 2 that the two sectors with the largest sacrifice ratio are residential investment and durables consumption. This is not surprising considering that residential investment is only 4.5 percent of the economy but contributes one quarter of the aggregate response. On the other hand, services consumption has the smallest sacrifice ratio among those sectors with a significant response to monetary policy, which is not surprising given that the services consumption represents one-third of the economy. 
Table 2: Sacrifice ratios by sector

\begin{tabular}{lcc}
\hline \hline Sector & $\begin{array}{c}\text { Sacrifice ratio } \\
\text { (point est.) }\end{array}$ & $\begin{array}{c}\text { Sacrifice ratio } \\
\text { (upper band) }\end{array}$ \\
\hline \hline Durables consumption $(C D U R)$ & -21.44 & -3.83 \\
Nondurables consumption $(C N D U R)$ & -8.96 & -1.47 \\
Services consumption $(C S E R)$ & -2.54 & -0.07 \\
Residential investment $(I R E S)$ & -54.41 & -15.17 \\
Structures investment $(I S T R U C)$ & 1.89 & - \\
Equipment and software investment $(I E Q U I P)$ & -16.29 & - \\
\hline \hline
\end{tabular}

Note: The sacrifice ratio using the point estimates corresponds to the area between the $\mathrm{x}$ axis and the normalized impulse response function during the period between the monetary policy shock and the minimum of the quarter in which the series returns to its baseline level or 20 quarters. The normalized impulse response corresponds to the standard impulse responses divided by the average share of each sector in real GDP during the last six quarters of the data. The sacrifice ratio using the upper band is the area between the $\mathrm{x}$ axis and the upper confidence band of the normalized impulse response function computed during the quarters for which the impulse response function is statistically different from zero.

Overall, despite the usual amount of noise present in the estimation of impulse response functions, we observe some interesting differences in the effect of monetary policy across sectors. The evidence reported above suggests that monetary policy has its largest effect on durables consumption and residential investment; structures investment and equipment and software investment are much less sensitive. These findings are consistent with the observed behavior of the U.S. economy after the hightech crisis. The low sensitivity of equipment and software investment to monetary policy can explain why the IT sector has remained depressed despite the sharp interest rate cuts by the Federal Reserve, while the high sensitivity of the durables consumption and residential investment is also consistent with the temporary booms experienced by the housing and automobile sectors. Thee results are not significantly affected by excluding the last two years from the sample. The only effect of this modification is that equipment and software investment becomes slightly more sensitive to monetary policy, which has a statistically significant effect between the sixth and ninth quarters. The relative sensitivity of equipment and software is, however, unaffected. This evidence suggests that the latest episode is not particularly material in driving the results.

More generally, these differences across sectors imply that monetary policy has 
the potential to generate inter-sectoral transfers. These transfers can be particularly important if the monetary policy response is triggered by a sectoral shock because the change in interest rate can induce negative comovement between the sector affected by the shock and the interest rate-sensitive sectors. The transmission of a sectoral shock, the role played by monetary policy in its transmission, and the pattern of sectoral decoupling will be analyzed in the next section, which applies our methodology to the high-tech crisis.

\section{The transmission of a sectoral shock: the high- tech crisis.}

One of the main advantages of our methodology is that it allows us to identify the effect of sectoral shocks and the role that the monetary policy rule plays in their transmission. As previously explained, the crucial identification assumption is that all contemporaneous comovement across sectors is the result of the correlation of their structural innovations. This assumption, however, complicates the interpretation of the sectoral shocks and the impulse response functions. Typically, the impulse response functions plot the response of the VAR to a structural shock to one of the variables. Under the standard recursiveness approach, the structural shocks are orthogonal by assumption, so the source of the innovation is clearly determined. In our case, the structural innovations to different sectors are correlated, ${ }^{20}$ so a sectoral shock will typically coincide with simultaneous shocks to the rest of the sectors. It is this correlation which generates the contemporaneous comovement observed in the impulse responses.

As described in section 2.2, there are basically two ways of understanding the correlation of the structural innovations. The first is to assume that it corresponds to the correlation among the sectoral shocks; under this view, there are no idiosyncratic shocks. The second is to assume that the correlation is due to the presence of an aggregate shock; under this view, the structural innovations correspond to the combination of an aggregate shock and an idiosyncratic sectoral shock. Certainly, there is no empirical way of distinguishing between these two worlds. The true nature of the

\footnotetext{
${ }^{20}$ We still maintain the assumption that the structural shocks to monetary policy and prices are orthogonal to the rest of the shocks and among themselves.
} 
sectoral shocks, however, must lie somewhere in the middle. Looking at the effect of a sectoral shock under both extreme identification assumptions gives us some bounds within which the true impulse response function must lie. We believe that this is an important step forward with respect to the current state of the literature, which makes no attempt to identify the effect of these kinds of perturbations.

We applied our methodology to explore the effect of a shock to equipment and software investment which we associate with the kind of shock that triggered the recent U.S. high-tech crisis. In order to understand the role of monetary policy in the transmission of the shock, we document both the impulse response functions of the economy predicted by the full VAR and the counterfactual impulse response functions obtained when the monetary policy channel of the VAR is suppressed. We also analyze the dynamic response of the economy if, in response to the shock to equipment and software investment, the monetary authority reacted with a monetary policy shock targeted at stabilizing output within a specific time horizon (considering the dynamics as given): we simulate the results for horizons of 4, 8, and 12 quarters.

Overall, the results obtained under the two alternative identification assumptions show that the automatic reaction of the monetary authority has a significant role in the propagation of sectoral shocks. We also find that the predicted response of our VAR shows some remarkable similarities to the events observed in the U.S. in recent years. These similarities are more profound when we assume that, in addition to its automatic response, the monetary authority reacts to the fall in GDP with a monetary policy shock.

\subsection{Correlated sectoral shocks}

The impulse response functions of the economy and its different sectors to a one standard deviation correlated innovation to equipment and software investment are reported in Figures 8 and 9. ${ }^{21}$ Figure 8 shows that the shock has a significant impact on GDP, which falls by 54 basis points from its baseline level after two quarters. According to the Taylor rule, the contemporaneous response of the monetary authority is a reduction of the funds rate of 5 basis points. As activity keeps contracting

\footnotetext{
${ }^{21}$ The effect of the correlated sectoral shock is determined as follows. Let $R$ represent the correlation matrix of the structural innovations. That is:

$$
R=\operatorname{diag}(\Sigma)^{-1 / 2} \Sigma \operatorname{diag}(\Sigma)^{-1 / 2}
$$
}


after the initial shock, the monetary authority keeps reducing the interest rate until achieving a fall of 40 basis points two quarters after the shock. There is a significant fall in prices which still persists after 20 quarters. Notice that the shock by itself is highly persistent and that output remains below its natural level for several years.

As the correlations across sectors are typically positive, almost every sector experiences a contraction as a result of the shock to equipment and software investment. However, the speed of recovery is significantly different across sectors: services consumption, durables consumption, and residential investment return to their baseline level much faster than nondurables consumption, equipment and software investment, and structures investment. As discussed above, the former are precisely those sectors with the highest sensitivity to monetary policy. So their fast recovery can be attributed to the effect of the fall in interest rates resulting from the automatic response of the monetary authority. Likewise, as discussed above, equipment and software investment had a small response to monetary policy, so it is not surprising that that sector seems to be unaffected by the reaction of the monetary authority and that it remains in recession for a significant length of time. This evidence suggest that monetary policy stabilizes output in response to a shock to a sector with low interest rate sensitivity by inducing significant transfers towards sectors with high interest rate sensitivity.

Figures 10 and 11 show the counterfactual impulse response functions obtained when the monetary policy part of the VAR is suppressed. Figure 10 shows the impulse response functions only of equipment and software investment and aggregate GDP, and Figure 11 shows the impulse response functions of all the sectors. These figures show that, as expected, output recovery is considerably slower without the

Column $j$ of $R$ contains the correlations between sector $j$ and the rest of the sectors:

$$
R_{. j}=\left(\begin{array}{c}
\rho_{1 j} \\
\vdots \\
\rho_{N j}
\end{array}\right)
$$

Let $\sigma_{j}$ be the standard deviation of the structural innovation to sector $j$. The impulse response function to a one standard deviation shock to sector $j$ is then determined by setting:

$$
\left(\begin{array}{c}
Y_{10} \\
\vdots \\
Y_{N 0}
\end{array}\right)=\sigma_{j}\left(\begin{array}{c}
\rho_{1 j} \\
\vdots \\
\rho_{N j}
\end{array}\right) \text {. }
$$




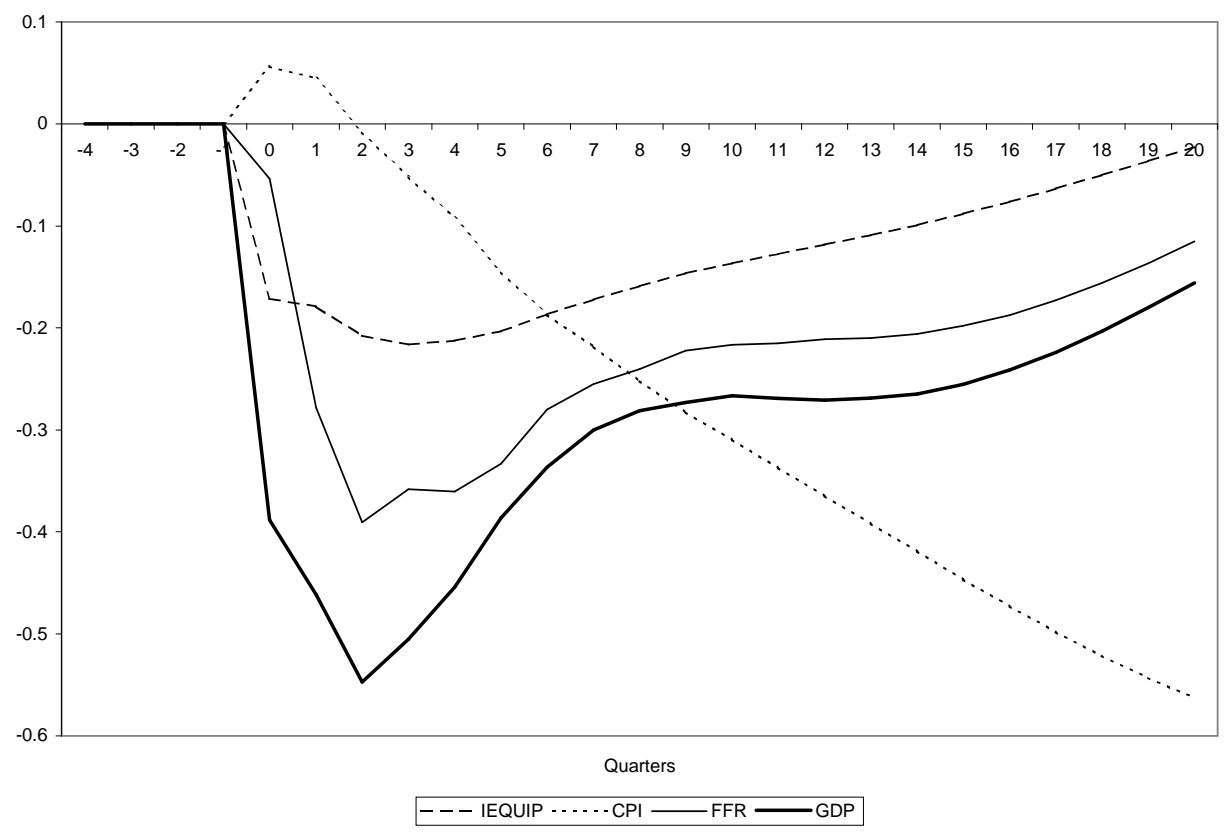

Figure 8: Aggregate effects of a correlated sectoral shock

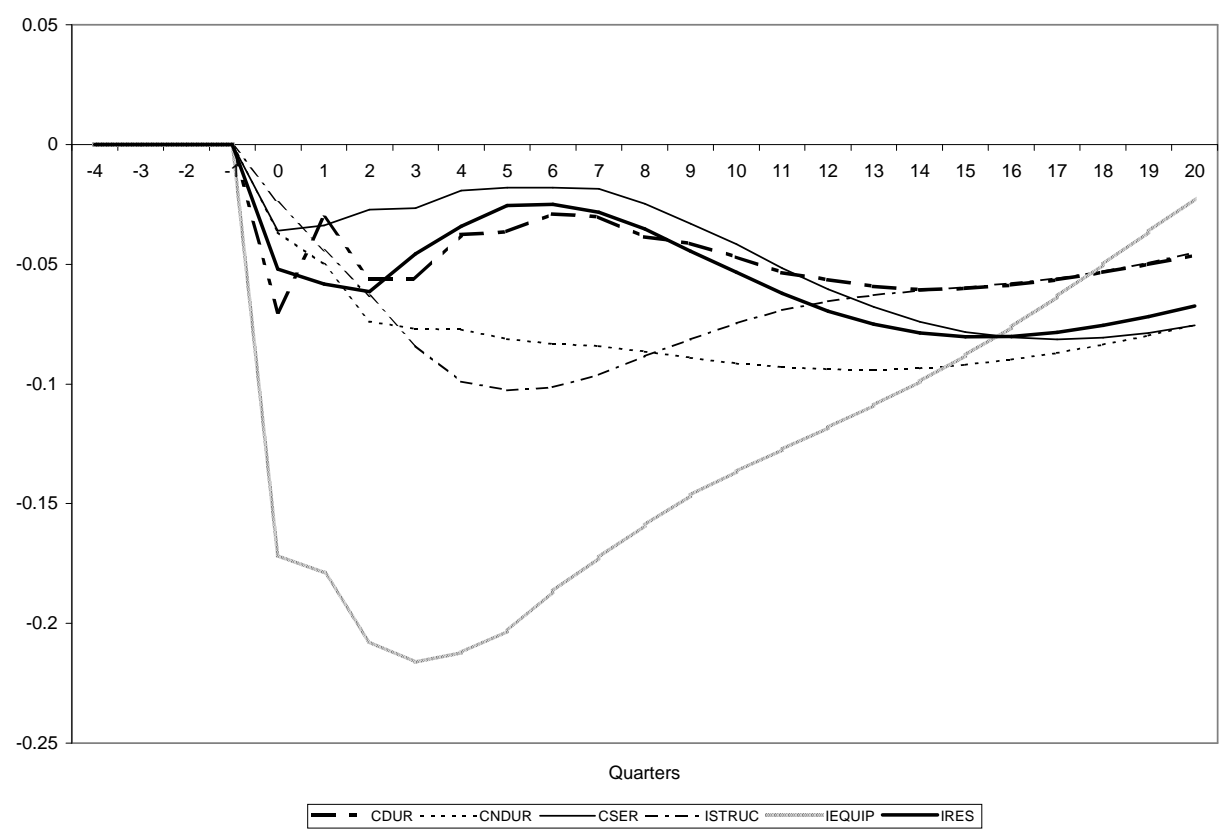

Figure 9: Sectoral effects of a correlated sectoral shock 


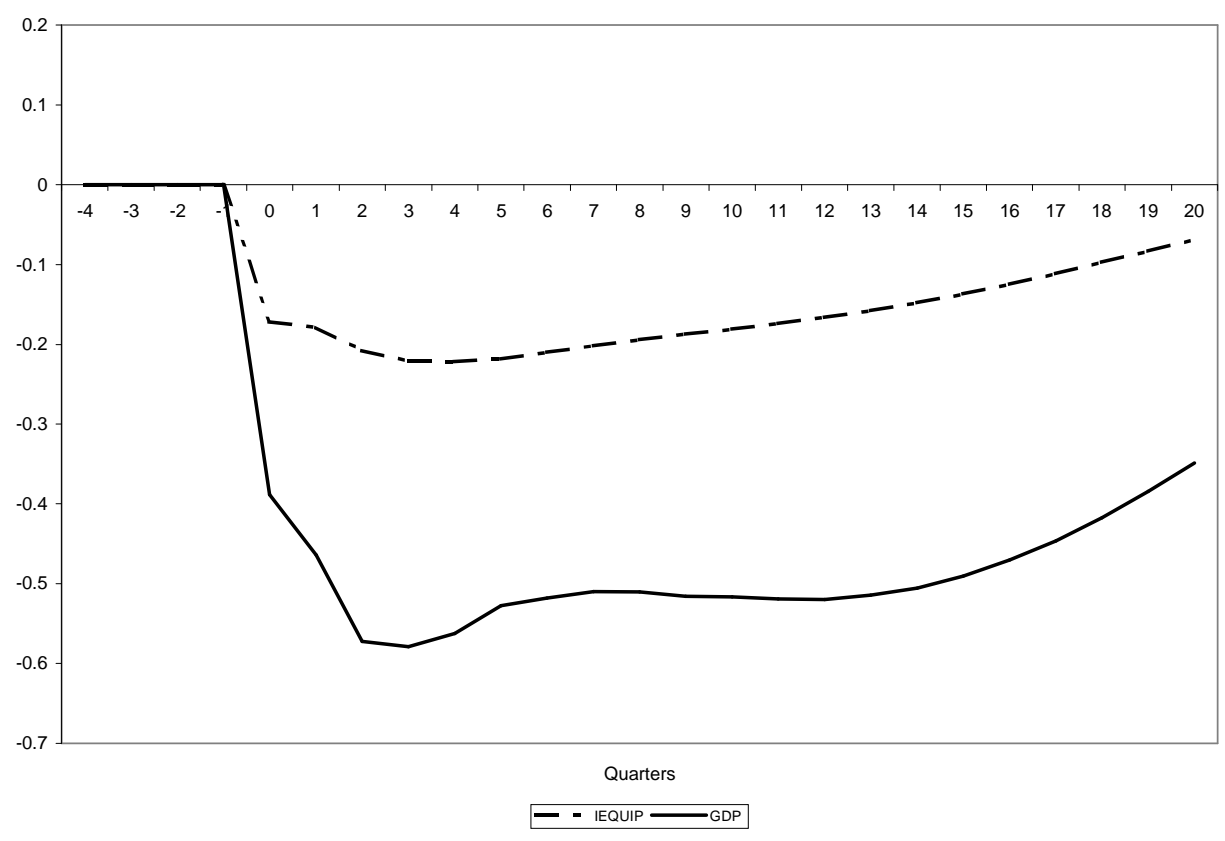

Figure 10: Aggregate effect of a correlated sectoral shock, no monetary policy case

stimulus of the reduction in interest rates. More interestingly, the sectoral impulse response functions in Figure 11 provide an interesting benchmark: comparing them with those in Figure 9 allows us to determine the part of the sectoral dynamics that are affected by monetary policy. The comparison shows that the quick recoveries of durables consumption, services consumption, and residential investment observed in Figure 9 are exclusively due to the effect of monetary policy: without an active monetary policy, the effect of the shock to equipment and software investment on these sectors is large and long-lasting. In addition, an active monetary policy makes these sectors significantly less correlated with less interest-sensitive sectors like structures investment.

Figures 12 and 13 show the impulse response functions of the economy and the sectors to a different counterfactual policy exercise: we analyze what happens to the economy if the monetary authority's response to the sectoral shock goes beyond the automatic reaction dictated by its Taylor rule. ${ }^{22}$ In particular, we ask what happens if the monetary authority responds with a monetary policy shock aimed at stabilizing aggregate output in less than two years (eight quarters). Figure 12 shows that the

\footnotetext{
${ }^{22}$ This exercise would be affected by the Lucas critique if the shock revealed any new information about the monetary authority's preferences. We assume that this is not the case.
} 


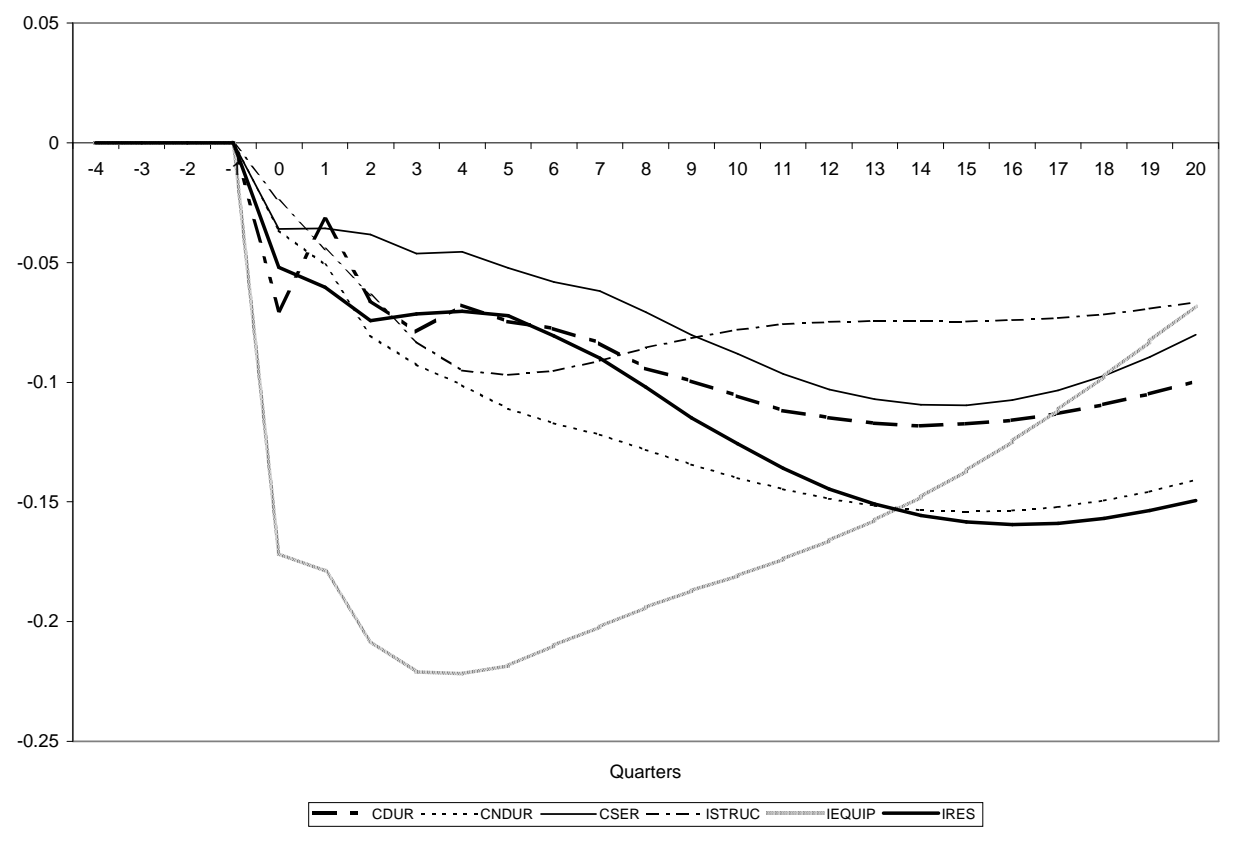

Figure 11: Sectoral effects of a correlated sectoral shock, no monetary policy case

necessary monetary policy shock is 47 basis points, which, added to the automatic response dictated by the policy rule ( 5 basis points), induces a contemporaneous decline in interest rates of 52 basis points. As this swift contemporaneous response induces a fast recovery in aggregate activity, the interest rate does not fall much further in future periods; it declines only by an additional 34 basis points the next quarter before starting to return to its baseline level. However, Figure 13 shows that this swift policy reaction is unable to stabilize the equipment and software investment sector: the recession in this sector still continues after two years. On the other hand, there is a boom in residential investment and durables consumption, which recover after three quarters and enter into an expansion thereafter. The effect on inflation is small.

\subsection{Idiosyncratic sectoral shocks}

As previously mentioned, our methodology also allows us to determine the response of the economy and its different sectors to an orthogonal innovation to equipment and software investment. Because in this case the innovation has no contemporaneous effect on the other sectors, its aggregate effect has to be smaller than in the correlated 


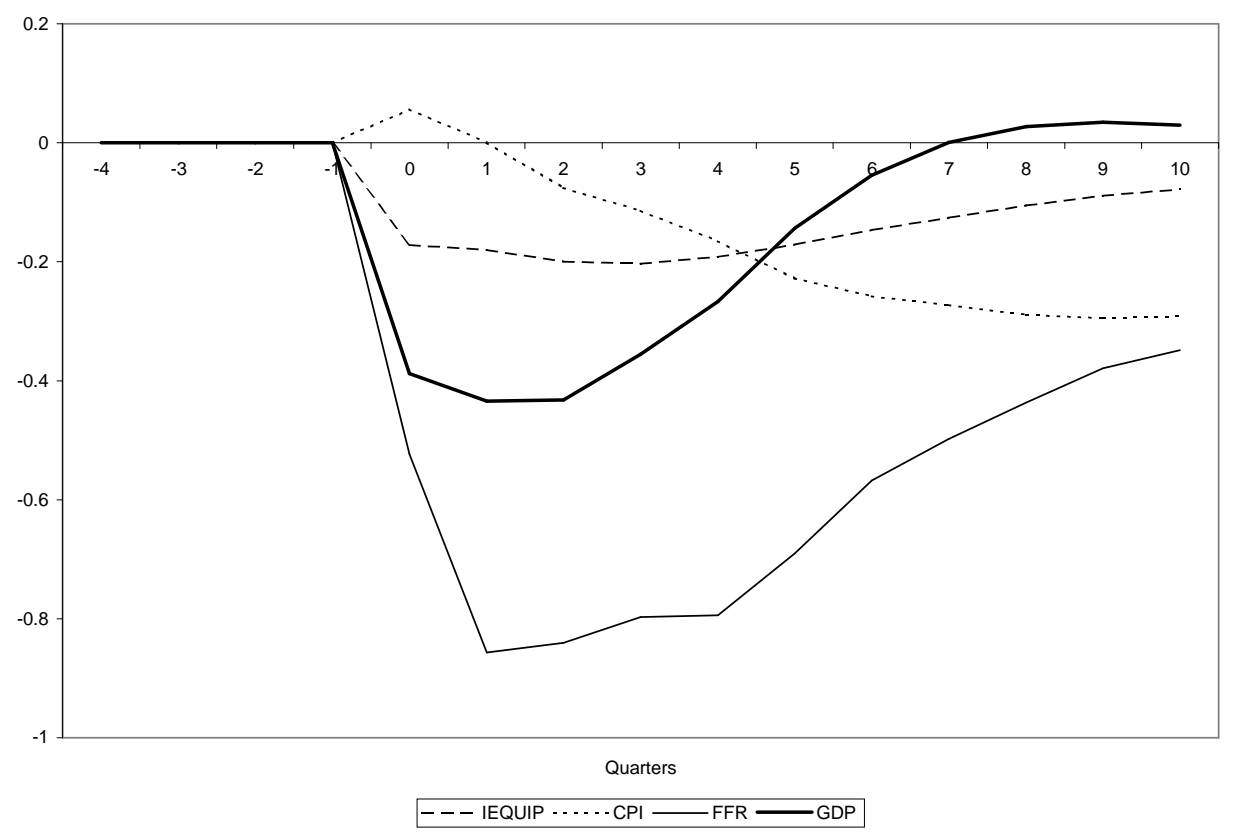

Figure 12: Aggregate effect of output stabilization policy (correlated sectoral shock)

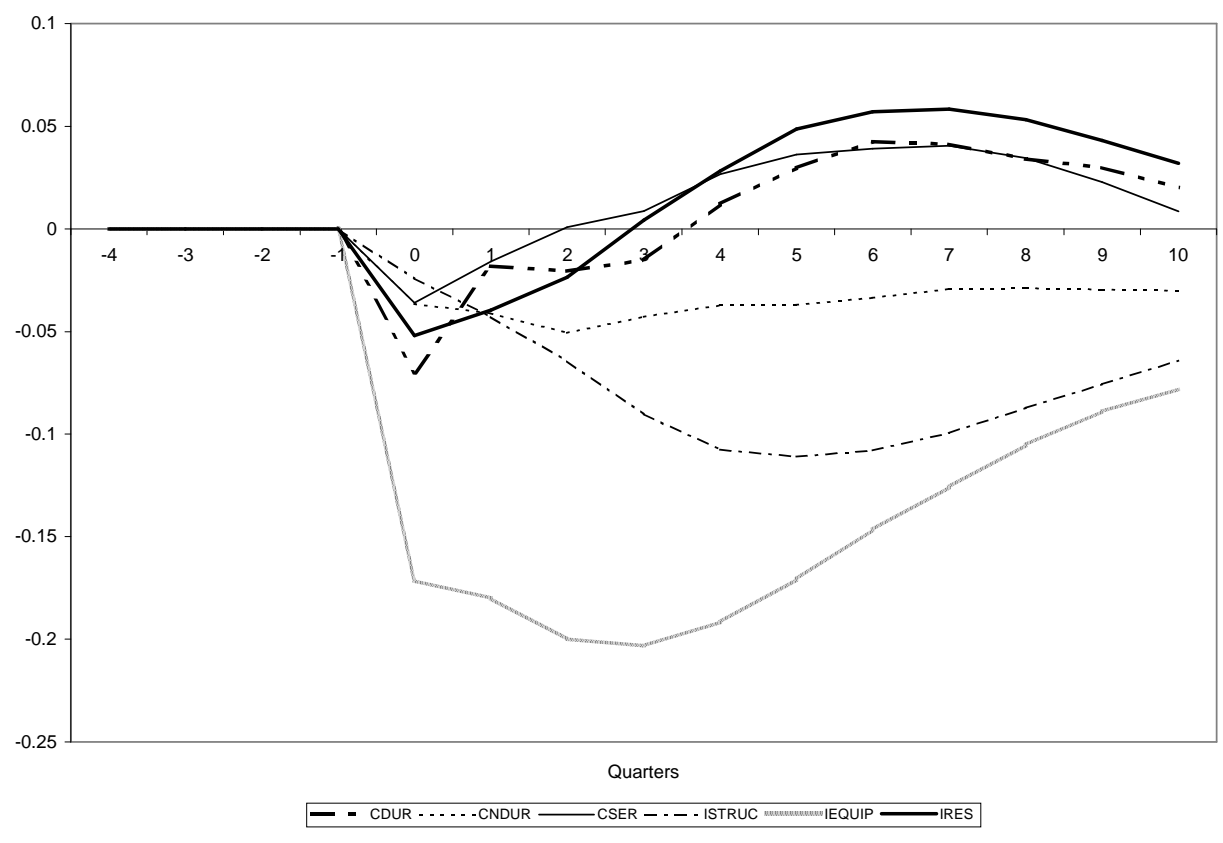

Figure 13: Sectoral effect of output stabilization policy (correlated sectoral shock) 
case. In this sense, this exercise gives us a lower bound on the true effect of a sectoral shock. $^{23}$ Next, we discuss some general aspects of the results obtained in this case. For a more comprehensive discussion see Raddatz and Rigobon (2003b).

The sectoral shock induces a significant decline in both aggregate GDP and interest rates. But, as expected, the response is quantitatively smaller than in the correlated case: GDP falls by about 28 basis points after three quarters, the interest rate responds contemporaneously with a decline of only 2 basis points, after which it keeps falling and reaches a maximum decline of 21 basis points. This small decline in interest rates is enough to stabilize the output of sectors with high interest rate sensitivity, but it is not enough to stop the recession in the rest of the economy: the effect of the shock on durables consumption, services consumption, and residential investment, is considerably smaller than its effect on nondurables consumption, structures investment, and equipment and software investment.

Table 3 provides an overall comparison of the contemporaneous response of interest rates for the cases of a correlated and an independent sectoral shocks. The table presents the contemporaneous decline in interest rates under four different stances of monetary policy: automatic response implied by the Taylor rule, and aggregate output stabilization within four, eight, and twelve quarters. The results previously discussed correspond to the automatic response and to the eight-quarter stabilization. As expected, the shorter the targeted stabilization period, the larger the required contemporaneous drop in interest rates. As also expected, the required declines in interest rate are systematically smaller in the independent sectoral shock case. More interestingly, the decline required to stabilize output within eight quarters has a similar magnitude than the actual decline in the interest rates induced by the Fed during 2001. As documented in section 3.2.2, the structural residuals obtained with our methodology indicate two consecutive shocks to equipment and software investment during the first two quarters of 2001: a 2.6 standard deviation shock and a 3.9 standard deviation shock. A back-of-the-envelope calculation suggests that the size of the monetary policy shock required to stabilize aggregate output within two years should

\footnotetext{
${ }^{23}$ The structural VAR under the assumption that all sectoral correlations are generated by an aggregate shock is different from the structural VAR with unrestricted correlation of sectoral shocks. Therefore, the parameters of this VAR were estimated anew. The results obtained for the structural parameters, presented in the appendix, are remarkably similar to those obtained in the unrestricted VAR. This similarity implies that the covariance matrix of sectoral shocks is amenable to this kind of structure. In addition, it makes us very confident in our estimation procedure.
} 
Table 3: Decline in the federal funds rate in response to a shock to equipment and software investment ( $\mathrm{E} \& \mathrm{~S}$ Inv) (in basis points)

\begin{tabular}{lcc}
\hline \hline $\begin{array}{l}\text { Mon. Policy } \\
\text { Stance }\end{array}$ & $\begin{array}{c}\text { Correlated shock } \\
\text { to E \&S Inv }\end{array}$ & $\begin{array}{c}\text { Independent shock } \\
\text { to E \&S Inv }\end{array}$ \\
\hline \hline & & \\
Automatic Response & 5 & 2 \\
Stabilization in a year & 164 & 93 \\
Stabilization in two years & 52 & 38 \\
Stabilization in three years & 47 & \\
\hline \hline
\end{tabular}

be around 1.7 percentage points, with a total decline in interest rates of about 2.5 percentage points after two quarters. This amount roughly corresponds to half of the 4.75 percentage point decline in interest rates during 2001.

Overall, both assumptions about the correlations among sectoral shocks produce similar results. They show that a shock to equipment and software investment generates a significant decline in aggregate output and interest rates. The decline in interest rates resulting from the automatic response of the monetary authority-given by its Taylor rule-is enough to stabilize the output of sectors with high interest rate sensitivity, such as durables consumption and residential investment. If the monetary authority also reacted with a shock to the interest rate designed to stabilize output within a year, these sectors would experience a temporary boom. In none of these case, however, is monetary policy able to stabilize quickly the output of sectors that are less sensitive to monetary policy, such as equipment and software investment or structures investment.

\section{Conclusion}

In this paper we present a new methodology that allows us to investigate both the sectoral effects of monetary policy and its role in the transmission of sectoral shocks. We apply our methodology to the U.S. and demonstrate that there are interesting differences in the response to monetary policy among U.S. sectors. Moreover, we show that, due to these differences, a monetary policy rule aimed at stabilizing aggregate output and prices will have an asymmetric effect across sectors: sectors with high interest rate sensitivity will experience larger cyclical fluctuations than sectors with 
low sensitivity. Our results also suggest that the sectoral "transfers" involved are potentially significant. In other words, monetary policy will achieve stabilization only by inducing relatively large expansions and contractions in sectors with high interest rate sensitivity.

Our estimates indicate that the high-tech crisis in 2001 represented a shock of roughly $6.5(2.6+3.9)$ standard deviations. According to our estimates, the simultaneous automatic response of monetary policy would be between 6 and 17 basis points with a trough four quarters into the recession where the funds rate has been reduced between 70 and 117 basis points. On the other hand, if the monetary authority's objective were to recover aggregate output within eight quarters, the reaction to the shock would have been much larger. Our estimates suggest that the Fed should have dropped interest rates immediately by between 117 and 152 basis points. The path of interest rates would have implied that the interest rate should have been reduced by something between 177 and 259 basis points. These estimates indicate that after the high-tech crisis we should have expected that a relatively concerned Fed should have reduced the interest rate by a maximum of 2.5 percentage points. This is remarkably close to what the Fed's actual funds rate reduction. Furthermore, this estimate includes only the shocks associated with the high-tech crisis; clearly if we were able to disentangle the aggregate component implied by September 11 and the corporate governance issues ocassioned by Enron and others, the predicted interest rate reduction would have been much closer to the 4.5 percent funds rate reduction the Fed actually made.

From the policy point of view, our results indicate that monetary policy, unfortunately, is not well equipped to deal with sectoral shocks. Indeed, it produces large reallocations. Therefore, it cannot deal with a sectoral recession, especially if that sector is not interest-sensitive and if the recession is due to overcapacity. Monetary policy is, therefore, better equipped to deal with aggregate shocks while fiscal policy is more appropiate for dealing with sectoral shocks. Similar points were discussed in Europe before the reunification (Dornbusch et al. (1998)). Further research should apply the methodology developed here to evaluate the recent experiences in the Euro zone.

In this paper we have used demand components to make claims about sectors. This is, indeed, a short cut, but one that we feel provides very interesting insights into the dynamic responses of the various components to monetary policy. However, 
future research should replicate these results using sectoral output or employment.

Several other questions are left unanswered in this paper. Probably the most important is why different sectors have different sensitivities to monetary policy. We can speculate that differences in the importance of financial constraints, price stickiness, or durability are potential causes to be explored, and they also should form part of future research.

Finally, from a methodological point of view, we see our methodology as a useful tool to explore some unanswered questions about the effects of monetary policy and to test different hypotheses about the behavior of the monetary authority. For example, within academic and policy circles it is frequently speculated that the monetary authority pays more attention to certain sectors (for example, residential investment) to decide the stance of monetary policy. This hypothesis can be easily tested in our framework by relaxing the assumption that the Taylor rule followed by the monetary authority depends only on aggregate output and prices. We plan to tackle the question of distributional aspects in the Taylor rule in future research. 


\section{References}

Barth, Marvin and Valery Ramey, "The cost channel of monetary policy," 2001. Mimeo, UC San Diego.

Bernanke, Ben and Alan Blinder, "The Federal Funds Rate and the Channels of Monetary Transmission," American Economic Review, September 1992, 82 (4), 901-921.

- and Ilan Mihov, "Measuring Monetary Policy," Quarterly Journal of Economics, August 1998, 113 (3), 869-902.

- and Mark Gertler, "Inside the Black Box: the credit channel of monetary policy," Journal Economics Perspectives, Fall 1995, 9 (4), 27-48.

Christiano, Lawrence and Martin Eichenbaum, "Identification and the Liquidity Effect of a monetary policy shock," in Alex Cukierman and Zvi Hercowitz, eds., Political economy, growth, and business cycles, MIT Press, 1992, chapter 12, pp. $335-372$.

_ , _, and Charles Evans, "The effects of monetary policy shocks: evidence from the flow of funds," Review of Economics and Statistics, 1996, 78 (1), 16-34.

_ , _, and _ , "Identification and the effects of monetary policy shocks," in Mario Blejer, Zvi Eckstein, Zvi Hercowitz, and Leonardo Leiderman, eds., Financial Factors in economic stabilization and growth, Cambridge University Press, 1996, chapter 2, pp. 36-74.

_ , _ , and _ , "Monetary policy shocks: what have we learned and to what end?," in James Taylor and Michael Woodford, eds., Handbook of Macroeconomics, Vol. 1A, North Holland: Elsevier, 1999, chapter 2.

Dedola, Luca and Francesco Lippi, "The Monetary Transmission Mechanism: Evidence from the Industries of Five OECD Countries," July 2000. CEPR Discussion Paper.

Dornbusch, Rudiger, Carlo Favero, and Francesco Giavazzi, "The Immediate Challenges for the European Central Bank," 1998. NBER WP 6369. 
Faust, Jon, "The robustness of identified VAR conclusions about money," CarnegieRochester Conference Series on Public Policy, 1998, 49, 207-244.

_, John Rogers, Eric Swanson, and Johathan Rigth, "Identifying the effects of monetary policy shocks on exchange rates using high frequency data," April 2003. NBER WP 9660.

Raddatz, Claudio and Roberto Rigobon, "Monetary Policy, Sectoral Shocks, and the High-Tech Crisis," June 2003. in Raddatz, Claudio E. "Essays in Macroeconomic Volatility", PhD Thesis, MIT.

_ and _ , "Monetary Policy, Sectoral Shocks, and the High-Tech Crisis," July 2003. NBER WP 9835.

Rigobon, Roberto and Brian Sacks, "Delay in Monetary policy. Theory and evidence," 1998. Manuscript, MIT.

Romer, David and Christina Romer, "Does monetary policy matter? A new test in the spirit of Friedman and Schwartz," in "NBER Macroeconomic Annual, 1989," MIT Press, Cambridge, 1989, pp. 121-170.

Rudebusch, Glenn, "Do Measures of monetary policy in a VAR make sense?," International Economic Review, November 1998, 39 (4), 907-931.

Sims, Christopher, "Comparison of Interwar and Postwar business cycles: monetarism reconsidered," American Economic Review, May 1980, 70 (3), 250-257.

_ , "Interpreting the macroeconomic time series facts: the effects of monetary policy," European Economic Review, 1992, 36 (5), 975-1000.

Strongin, Steven, "The Identification of Monetary Policy Disturbances: Explaining the Liquidity Puzzle," Journal of Monetary Economics, August 1995, 35 (3), 463497.

Uhlig, Harald, "What are the Effects of Monetary Policy on Output? Results from an Agnostic Identification Procedure," 1999. Tilburg Center for Economic Research Discussion Paper: 9928. 


\section{APPENDIX}

\section{A Data}

Data for the estimation were obtained from the Bureau of Economic Analysis and the Federal Reserve Bank of St. Louis. The GDP data are quarterly. Quarterly values for the federal funds rate and the CPI correspond to the quarterly averages of monthly data. The GDP data are expressed in levels, deflated by the CPI, ${ }^{24}$ and expressed as a fraction of the last six quarters of real GDP averaged, which is therefore defined as the baseline level. Therefore, the impulse responses correspond to percentage deviations from this baseline. ${ }^{25}$ The CPI and the FFR are expressed in percentage points. The data were de-trended and de-meaned previous to estimation (using a linear trend). The results are similar if the trend and constants are estimated in the VAR.

\section{B Estimation of bands}

The confidence bands for the impulse response functions reported in the paper were built by bootstrapping. The detailed procedure is as follows. Let $\theta$ be the vector of parameters of the structural model. The estimators of these parameters $(\hat{\theta})$ were obtained by maximum likelihood; therefore:

$$
\hat{\theta}=\arg \max _{\theta} L(y \mid \theta)
$$

These estimators are asymptotically normally distributed. Their asymptotic covariance matrix corresponds to the information matrix:

$$
\operatorname{Asy} \operatorname{Var}(\hat{\theta})=-\left\{\frac{\partial^{2} L(y \mid \hat{\theta})}{\partial \hat{\theta} \partial \hat{\theta}^{\prime}}\right\}^{-1}
$$

\footnotetext{
${ }^{24}$ The results are similar if the GDP deflator is used instead.

${ }^{25}$ The results are qualitatively similar if the VAR is estimated in logs. We checked these results only using the two-step procedure, as the estimation is computationally burdensome. It requires using the share data at each point in time to recover the aggregate log GDP from the sectoral $\log$ outputs. This aggregation is necessary because both prices and the monetary policy rule are assumed to depend only on aggregates. In the estimation, shares were considered as given.
} 
therefore:

$$
\hat{\theta} \stackrel{\text { dist }}{\rightsquigarrow} \mathcal{N}(\theta, \operatorname{Asy} \operatorname{Var}(\hat{\theta})) .
$$

For the bootstrap, we took 500 independent draws of the parameters according to the normal distribution above. For each set of parameters, we estimated the implied impulse response function. To construct the bootstrap bands, we filter $90 \%$ of the impulse responses with the smallest overall distance from the impulse response obtained with the point estimators: let $\Psi$ represent the impulse response function associated with the point estimators; $\Psi$ is a $(N+2) \mathrm{x} L$ matrix containing the impulse response function of each VAR series to a specific shock-where $L$ is the number of periods considered for the impulse response functions. Analogously, let $\Psi^{k}$ represent the impulse response matrix associated with the $k$ th draw from the normal distribution. Define the distance between these two impulse response matrices as:

$$
D_{k}=\left\|\Psi^{k}-\Psi\right\|^{2}=\sum_{i=1}^{N+2} \sum_{j=1}^{L}\left(\Psi_{i j}^{k}-\Psi\right)^{2} .
$$

Next, rank the bootstrap impulse responses according to this distance. The upper band reported in the paper corresponds to the impulse response at the 95th percentile level of this ranking, and the lower band corresponds to the impulse response at the 5th percentile level of this ranking. Therefore the bands represent a $90 \%$ confidence interval around the point estimates. ${ }^{26}$

\footnotetext{
${ }^{26}$ We select the bands in this manner because the impulse response functions of the different series in the VAR are not independent.
} 